\title{
Corrigendum: Characterisation of Highly Radiating Neon Seeded Plasmas in JET-ILW (2019 Nucl. Fusion 59 126031)
}

\author{
S Glöggler ${ }^{1,2}$, M Wischmeier ${ }^{1}$, E Fable $^{1}$, E R Solano ${ }^{3}$, M \\ Sertoli $^{1,8}$, M Bernert ${ }^{1}$, G Calabrò ${ }^{4}$, M Chernyshova ${ }^{5}$, A Huber ${ }^{6}$, \\ E Kowalska-Strzęciwilk ${ }^{5}$, C Lowry ${ }^{7}$, E de la Luna ${ }^{3}$, C F Maggi ${ }^{8}$,

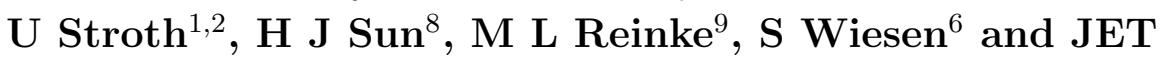 \\ Contributors* \\ ${ }^{1}$ Max Planck Institute for Plasma Physics, Boltzmannstraße 2, 85748 Garching bei \\ München, Germany \\ ${ }^{2}$ Physik-Department E28, Technische Universität München, 85747 Garching bei \\ München, Germany \\ ${ }^{3}$ Laboratorio Nacional de Fusión, CIEMAT, 28040 Madrid, Spain \\ ${ }^{4}$ Department of Economics, Engineering, Society and Business Organization (DEIm), \\ University of Tuscia, Largo dell'Università snc, 01100 Viterbo, Italy \\ ${ }^{5}$ Institute of Plasma Physics and Laser Microfusion, 23 Hery Street, 01-497 Warsaw, \\ Poland \\ ${ }^{6}$ Forschungszentrum Jülich GmbH, Institut für Energie- und Klimaforschung - \\ Plasmaphysik, 52425 Jülich, Germany \\ ${ }^{7}$ European Commission, 1049 Brussels, Belgium \\ ${ }^{8} \mathrm{CCFE}$, Culham Science Centre, Abingdon, OX14 3DB, UK \\ ${ }^{9}$ Oak Ridge National Laboratory, Oak Ridge, TN 37831, USA \\ *See the author list of E. Joffrin et al. 2019 Nucl. Fusion 59 112021, \\ https://doi.org/10.1088/1741-4326/ab2276 \\ E-mail: stephan.gloeggler@ipp.mpg.de \\ April 2020
}

In the article [1] a typo was made in the legend of Figure 1 which has thus to be replaced by the Figure below. The experiments described in [2] (cited on page 12) were operated at neon seeding rates in the range $0-5 \cdot 10^{21} \mathrm{el} / \mathrm{s}$. Both typos had no impact on any presented result.

\section{Acknowledgments}

This work has been carried out within the framework of the EUROfusion Consortium and has received funding from the Euratom research and training programme 2014-2018 and 2019-2020 under grant agreement No 633053. The views and opinions expressed herein do not necessarily reflect those of the European Commission. 
Corrigendum: Characterisation of Highly Radiating Neon Seeded Plasmas in JET-ILW (2019 Nucl. Fusion

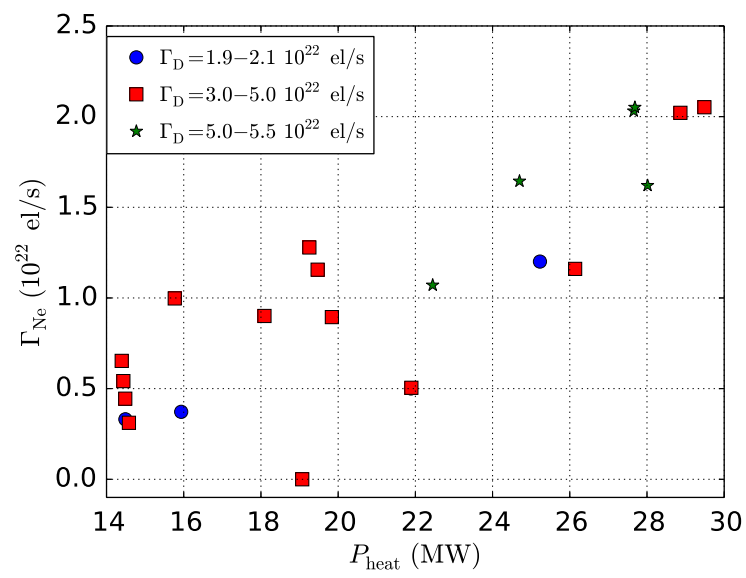

\section{References}

[1] Glöggler S, Wischmeier M, Fable E, Solano E R, Sertoli M, Bernert M, Calabrò G, Chernyshova M, Huber A, Kowalska-Strzęciwilk E, Lowry C, de la Luna E, Maggi C F, Stroth U, Sun H J, Reinke M L, Wiesen S and JET Contributors 2019 Nuclear Fusion 59126031

[2] Challis C D, Belonohy E, Czarnecka A, Frigione D, Giroud C, Graves J, Hobirk J, Huber A, Joffrin E, Krawczyk N, Lawson K, Mantsinen M, McClements K, O'Gorman T, Silburn S, Sips A, Solano E and JET Contributors 2017 Impact of neon seeding on fusion performance in JET ILW hybrid plasmas Proceedings of the 44th EPS Conference on Controlled Fusion and Plasma Physics, Belfast, 2017 P2.153 URL http://ocs.ciemat.es/EPS2017PAP/pdf/P2.153.pdf 